\title{
ROLE OF LIPOSOME IN NOVEL DRUG DELIVERY SYSTEM
}

\author{
Chandraprakash Dwivedi *, Rajni Yadav, Sandip Prasad Tiwari, Trilochan Satapathy, Amit Roy \\ Columbia Institute of Pharmacy, Tekari, Near Vidhansabha Raipur, C.G., 493111, India \\ *Corresponding author's Email: chandraprakash9009@gmail.com, Contact: 7415473164
}

\begin{abstract}
Liposome was found by Alec Bangham of Babraham Institute in Cambridge, England in 1965.In 1990; drugs with liposome and Amphotericin B were approved by Ireland. In 1995 America F.D.A approved liposor doxodubicin. In 1965s, it was well recognized that microscopic lipid vesicles, known as liposomes, could be utilized to encapsulate drugs and dyes for the purpose of systemic administration and drug targeting.Considerable progress was made in 1980s, in engeneering liposomes to circulate longer in blood and remain intact while doing so. The liposome a microscopic spherical particle formed by a lipid bilayer enclosing an aqueous compartment.An artificial microscopic vesicle consisting of an aqueous core enclosed in one or more phospholipid layers, used to convey vaccines, drugs, enzymes, or other substances to target cells or organs. Liposome was discovered about 40 years ago by Bangham and coworkersand was defined as microscopic spherical vesicles that form when phospholipids are hydrated or exposed to anaqueous environment Liposomes are microscopic vesicles composed of a bilayer of phospholipids or any similar amphipathic lipids. They can encapsulate and effectively deliver both hydrophilic and lipophilic substances 2.3 and may be used as a non.toxic vehicle for insoluble drugs. Liposomes are composed of small vesicles of phospholipids encapsulating an aqueous space ranging from about 0.03 to $10 \mu \mathrm{m}$ in diameter. The membrane of liposome is made of phospholipids, which have phosphoric acid sides to form the liposome bilayers. Liposomes can be manufacturing in different lipid comopsitions or by different method show variation in par. Size, size distribution, surface electrical potential, number of lamella, encapsulation efficacy, Surface modification showed great advantage to produce liposomes of different mechanisims, kinetic properties and biodistribution
\end{abstract}

Keywords: Liposome, Phospholipids, Bilayer

\section{INTRODUCTION}

Liposomes Microscopic phospholipid bubbles with a bilayered membrane structure - have received a lot of attention during the past 30 years as pharmaceutical carriers of great potential. ${ }^{1}$ More recently, many new developments have been seen in the area of liposomal drugs - from clinically approved products to new experimental applications, with gene delivery and cancer therapy still being the principal areas of interest. ${ }^{2}$ Liposomes are microscopic vesicles composed of a bilayer of phospholipids or any similar amphipathic lipids. They can encapsulate and effectively deliver both hydrophilic and lipophilic substances and may be used as a non-toxic vehicle for insoluble drugs. ${ }^{3}$ Liposomes are composed of small vesicles of phospholipids encapsulating an aqueous space ranging from about 0.03 to $10 \mu \mathrm{m}$ in diameter. ${ }^{4,5}$ The membrane of liposome is made of phospholipids, which have phosphoric acid sides to form the liposome bilayers.Liposomes can be manufacturing in different lipid comopsitions or by different method show variation in par. Size, size distribution, surface electrical potential, no. of lamella, encapsulation efficacy, Surface modification showed great advantage to produce liposomes of different mechanisims, kinetic properties and biodistribution. Products in the market Doxorubicin (Doxil, Myocet) (KS Kaposis sarcoma) Daunorubicin (Dauno Xome) Cytarabin artificial microscopic vesicle consisting of an aqueous core enclosed in one or more phospholipid layers, used to convey vaccines, drugs, enzymes, or other substances to target cells or organs. ${ }^{6}$ Liposomes are nano size artificial vesicles of spherical shape. They can be produced from natural phospholipids and cholesterol. Phospholipids combine with water immediately forms a bi-layered sphere $^{7}$ On this account Dr. Baumann Cosmetic produces only liposome products without perfume and without chemical preservatives. Exactly the same phospholipids which comprise the liposome membrane form the walls of skin cells. Similarly, the intercellular substance which is found between the skin cells is composed of phospholipids, ceramides, triglyceride, free fatty acids, cholesterol and water. If skin cells are slightly damaged or if the intercellular substance is lost through aggressive cleansing methods, liposomes are able to perfectly replenish the missing lipids. Therefore the combination of phospholipids, ceramides and other skin-endemic lipids.A liposome is a tiny bubble (vesicle), made out of the same material as a cell membrane. Liposomes can be filled with drugs, and used to deliver drugs for cancer and other diseases. $9,10,11$

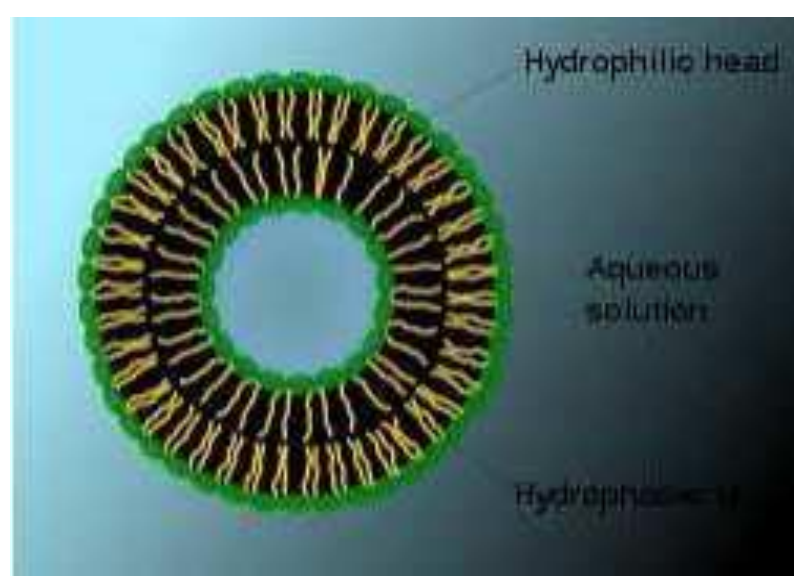

Figure 1: Scheme of a liposome formed by phospholipids in an aqueous solution 


\section{CLASSIFICATION}

Liposome are classified on the basis of:

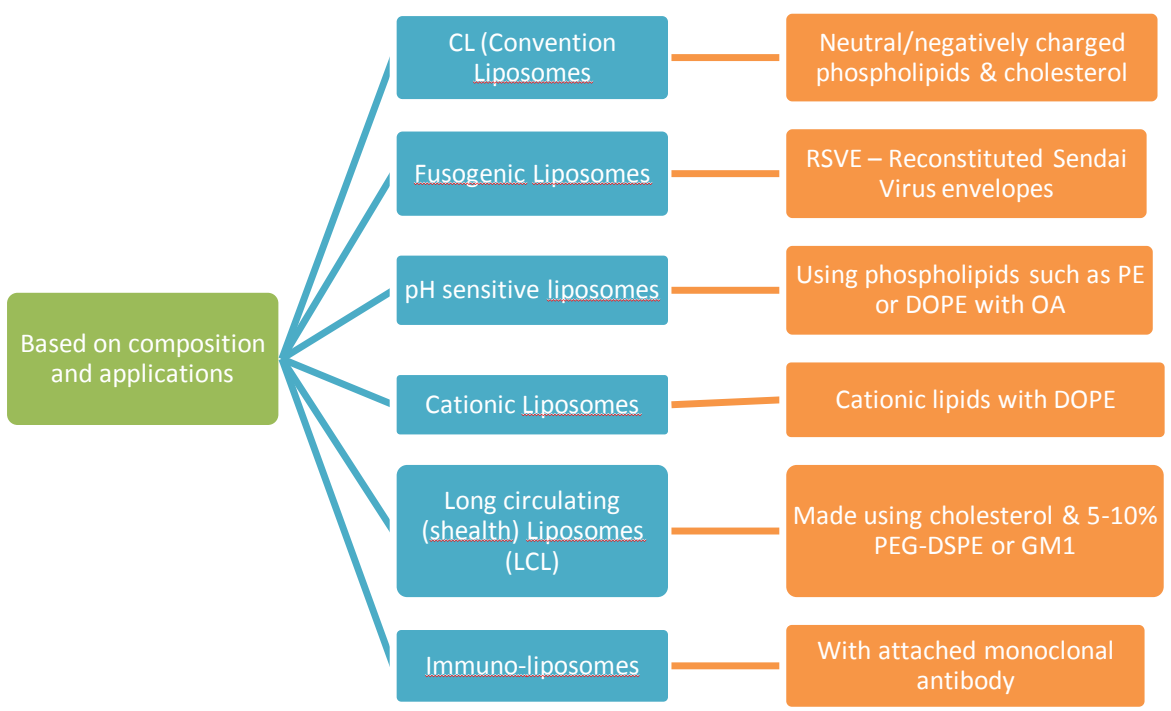

Fig 2: Structure of liposome based on composition and applications

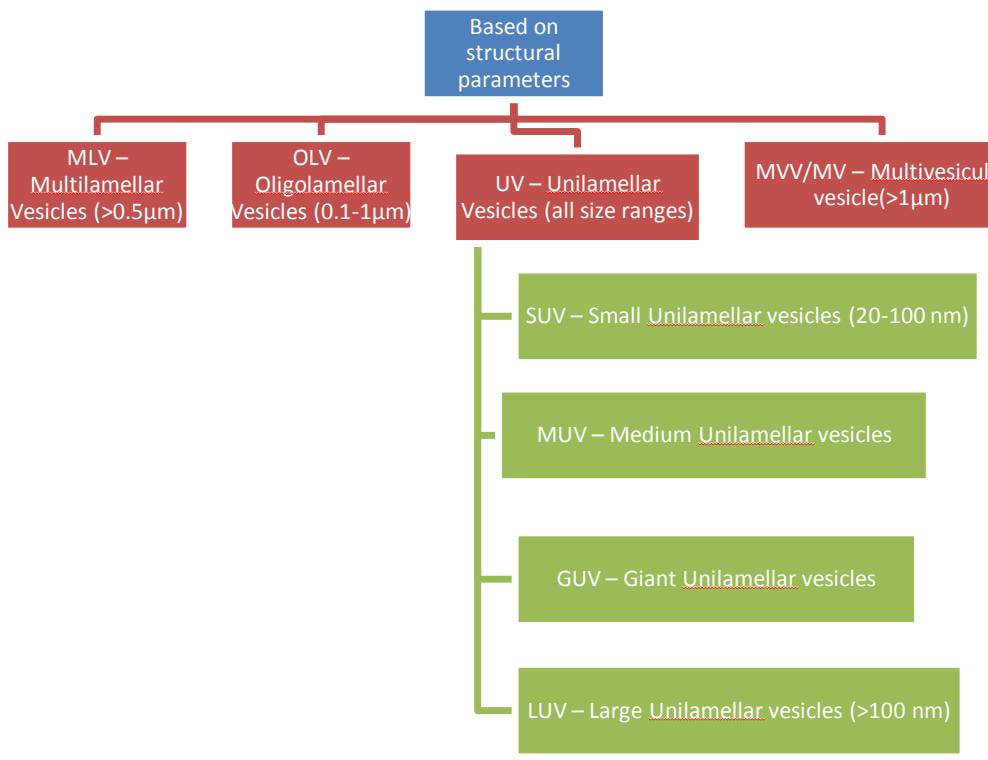

Fig 3: Structure of liposome based on structural parameters ${ }^{10}$

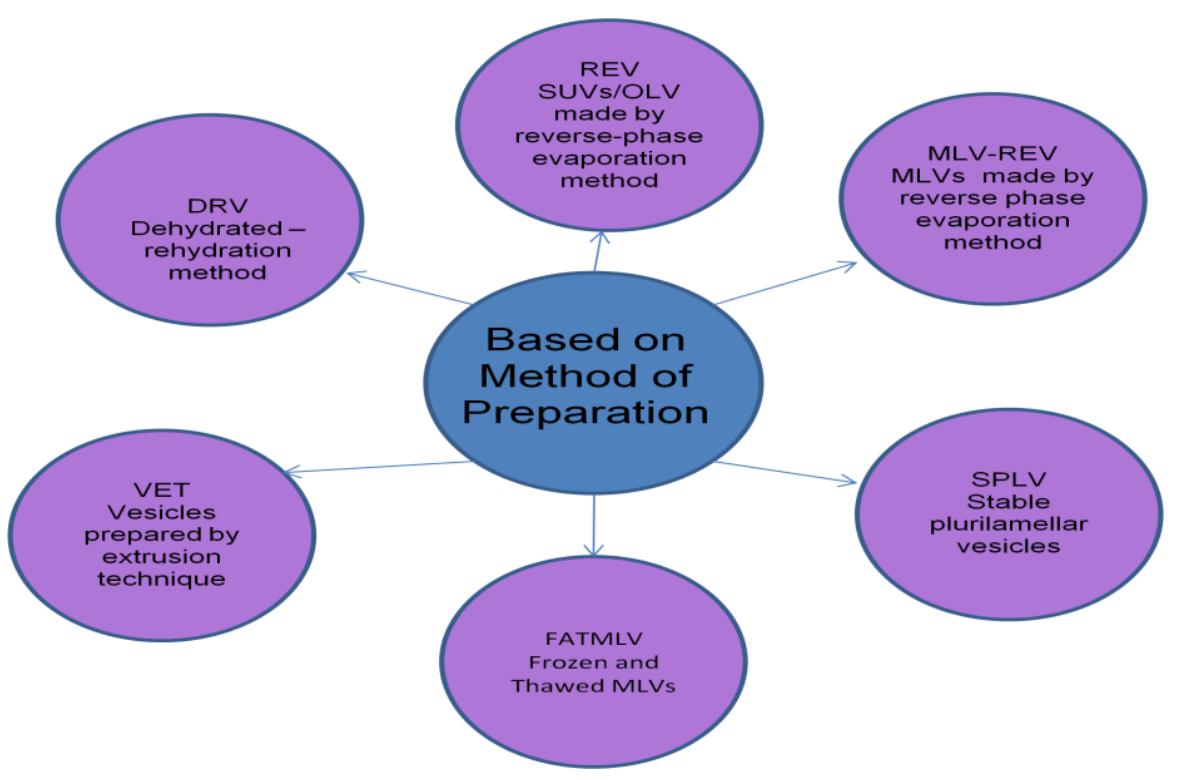

Fig 4: Structure of liposome based on methods of preparation 


\section{ATTRACTIVE BIOLOGICAL PROPERTIES OF LIPOSOMES}

- Liposomes are biocompatible.

- Liposomes can entrap water-soluble (hydrophilic) pharmaceutical agents in theirinternal water compartment and water-insoluble (hydrophobic) pharmaceuticals intothe membrane.

- Liposome-incorporated pharmaceuticals are protected from the inactivating effect of external conditions, yet do not cause undesirable side reactions.

- Liposomes provide a unique opportunity to deliver pharmaceuticals into cells or even inside individual cellular compartments.

- Size, charge and surface properties of liposomes can be easily changed simply by adding new ingredients to the lipid mixture before liposome preparation

\section{LAMELLA}

A Lamella is a flat plate like structure that appears during the formation of liposomes. The Phospholipid bilayer first exists as a lamella before getting convered into spheres. A Lamella is a flat plate like structure that appears during the formation of liposomes ${ }^{10}$

\section{ADVANTAGE}

- Flexibility in the structure in entrapment of water soluble as well as insoluble drugs.

- Biodegradability

- Efficient control of release.

- Resemblance to natural membrane structures.

- Increased targeting prospects. Biocompatible, completely biodegradable, non-toxic, flexible ,nonimmunogenic.

- Liposomes supply both a lipophilic environment and aqueous "milieu interne" in one system. Can protect encapsulated drug.

- Reduce exposure of sensitive tissues to toxic drugs. .

- Easy to construction.

- Increased efficacy and therapeutic index.

- Provides both targetting active and passive.

- Does not accumulate in heart and so there is no cardiotoxicity.

- Prevent oxidation of the drug.

\section{DISADVANTAGE}

- Production cost is high.

- Leakage and fusion of encapsulated drug / molecules.

- Sometimes phospholipid undergoes oxidation and hydrolysis like reaction.

- Short half-life.

- Low solubility.

- Fewer stables. The development of liposomes at industrial level is difficult due to its physiological and physicochemical instability.

- They are prone to degradation by oxidation and hydrolysis.

- Production cost is high.

- Leakage and fusion of encapsulated drug / molecules.
- Low solubility

- Fewer stables.

\section{COMPOSITION OF LIPOSOMES}

\section{A. Phospholipids}

Naturally occurring phospholipids used in liposome

- Phosphatidylethanolamine

- Phosphatidylcholine

- Phsphatidylserine<smiles>[R]C(=O)OCC(COP(=O)([O-])OCCC[N+](C)(C)C)OC([R])=O</smiles>

(2) Lecithin (phosphatidylcholine)

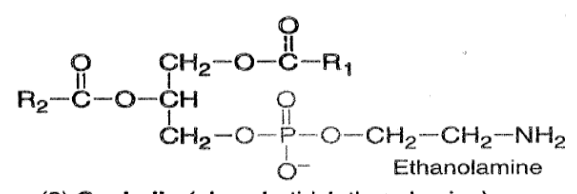

(3) Cephalin (phosphatidylethanolamine)

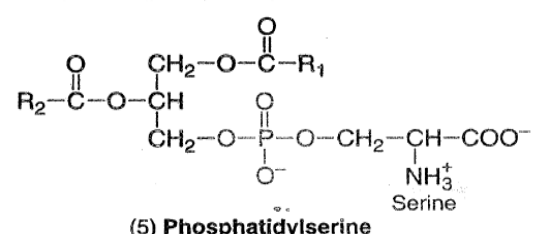

(5) Phosphatidylserine

- Synthetic phospholipids used in the liposomes are:

- Dioleoyl phosphatidylcholine

- Disteroyl phosphatidylcholine

- Dioleoyl phosphatidylethanolamine ${ }^{11}$

\section{B. Cholesterol}

Cholesterol can be incorporated into phospholipids membrane in very high concentration up to $1: 1$ or $2: 1$ molar ratios of cholesterol to phospatidylcholine. Being an amphipathic molecule, cholesterol inserts into the membrane with its hydroxyl group of cholesterol oriented towards the aqueous surface and aliphatic chain aligned parallel to the acyl chains in the center of the bilayers and also it increase the separation between choline head groups and eliminates the normal electrostatic and hydrogen bonding interaction. The phospholipids are arranged in such a way that the hydrophilic head is exposed outside and the lipophillic tails are aliened inside. This makes the liposomes water soluble molecules. ${ }^{11,12}$

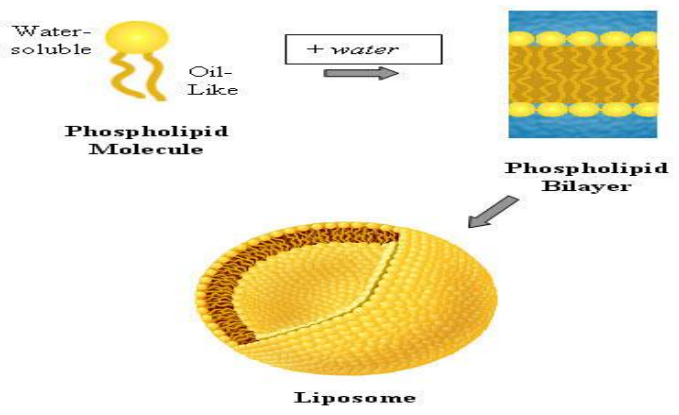

Fig. - 5: Structure of liposome overall composition ${ }^{7}$ 


\section{MECHANISM: - Liposome Formation}

$>$ As liposomes are made up of phospholipids, they are amhpipathic in nature and have ability to binds both aqueous and polar moiety. They have polar head and non polar tail.

$>$ The polar end is mainly phosphoric acid and it will bound to water soluble molecule.

$>$ In aqueous medium the molecules in self-assembled structure are oriented in such way that the polar portion of the molecule remain in contact with in polar environment and at same time shields the non polar part. Liposomes are formed when the thin films are hydrated and stacks of liquid crystalline bilayers become fluid and swells.

$>$ Once these vesicle get formed, a change in vesicle shape and morphology required energy input in the form of .... Sonic energy to get SUVs and mechanical energy to get LUVs.

> However, in aqueous mixtures these molecules are able to form various phases, some of them are stable and other remains in metastable form. ${ }^{12,13}$

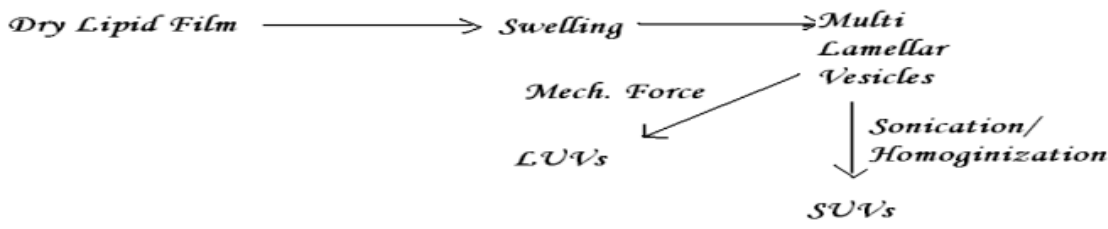

Fig 6: Mechanism of liposome preparation

\section{HANDLING OF LIPOSOMES-}

The lipids used in the preparation ofliposomes are unsatu rated and hencesusceptible to oxidation. Also volatile sol vents such as chloroformwhich are used will tend to evap orate fromthe containeThus liposomes must be stored in an inertatmosphere of nitrogen, and in the dark, inglass $\mathrm{v}$ essels with a securely fastened cap. ${ }^{13}$

\section{DRYING}

An important step involved in the preparation liposomes is the drying of the lipid. Large volume of organic solution of lipids is most easily dried in a rotary evaporator fitted with a

cooling coil and a thermo statically controlled water bath .Rapid evaporation of solvent
is carried out by
gentle warming
(20-40 degrees) under reduced pressure (400-700 mm Hg)

Rapid rotation of the solvent containing flask increases the surface area for evaporation In cases where sufficient vacuum is not attainable or if the concentration of lipids is particularly high, it may be difficult to remove the last traces of chloroform from the lipid film. Therefore, it is recommended as a matter of routine that after rotary evaporation, some further means is employed to bring the residue to complete dryness .Attachment of the flask to the manifold of lyophilize, and overnight exposure to high vacuum is a good method. ${ }^{14,15}$

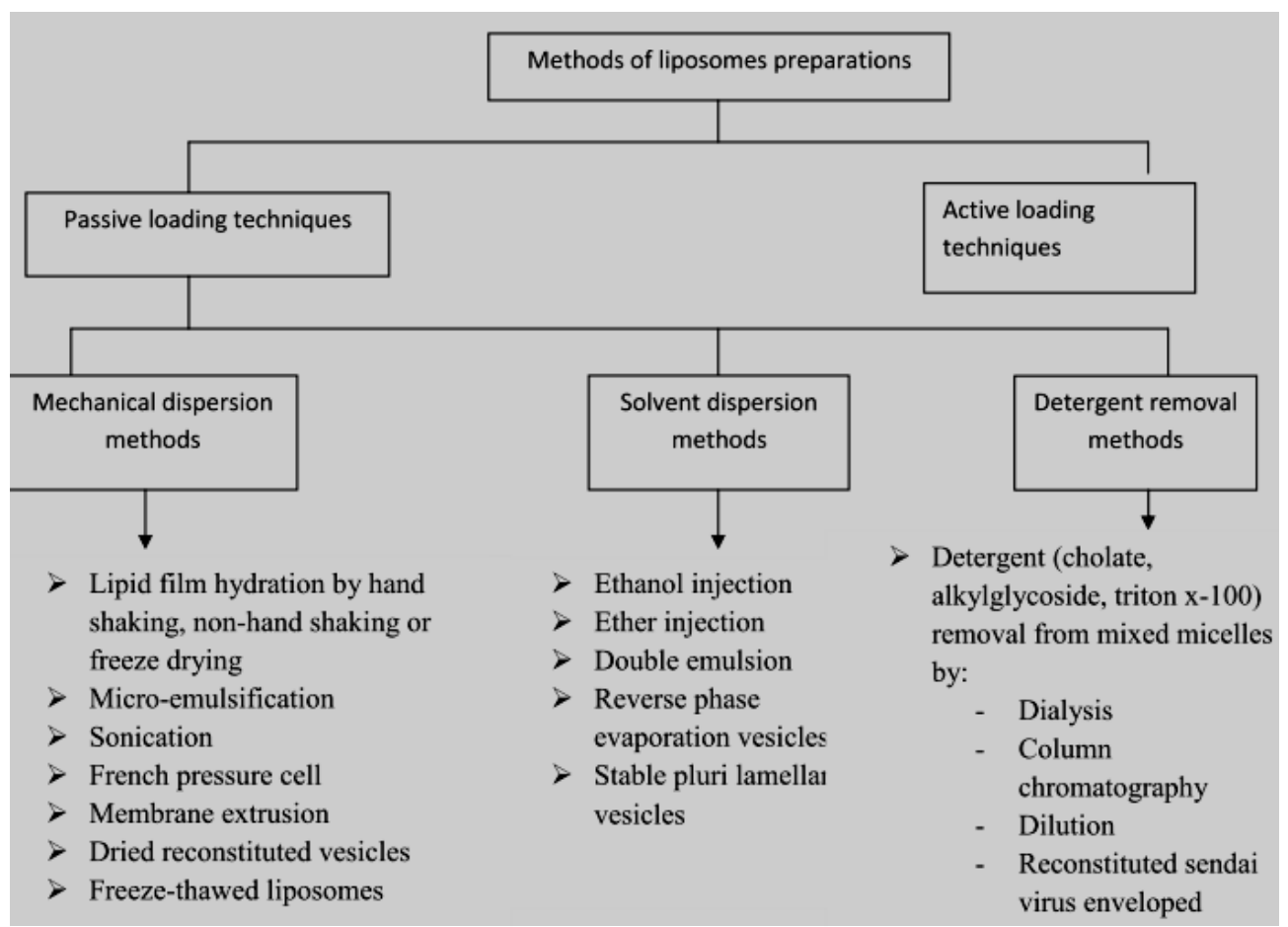

Fig-7: Different methods of liposomes preparations ${ }^{35}$ 


\section{METHOD OF PREPARATION BASED ON METHOD OF DISPERSION:}

- Mechanical dispersion

- Solvent dispersion methods

- Detergent removal methods

\section{MECHANICAL DISPERSION METHODS TYPES OF MODIFIED VESICLES}

- Lipids film hydration by hand shaking, non hand shaking and freeze drying

- Sonication unicellular liposomes

- Micro-emulsification liposomes

- French Pressure Cell liposomes

- Membrane Extrusion liposomes

- Dried reconstituted vesicles

- Freeze-thawed liposomes

- PH indused vesiculation

- Calcium indused fusion

\section{SOLVENT DISPERSION METHODS}

- Ethanol injection

- Ether injection

- Double emulsion vesicles

- Reverse phase evaporation vesicles

- Stable plurilamellar vesicles
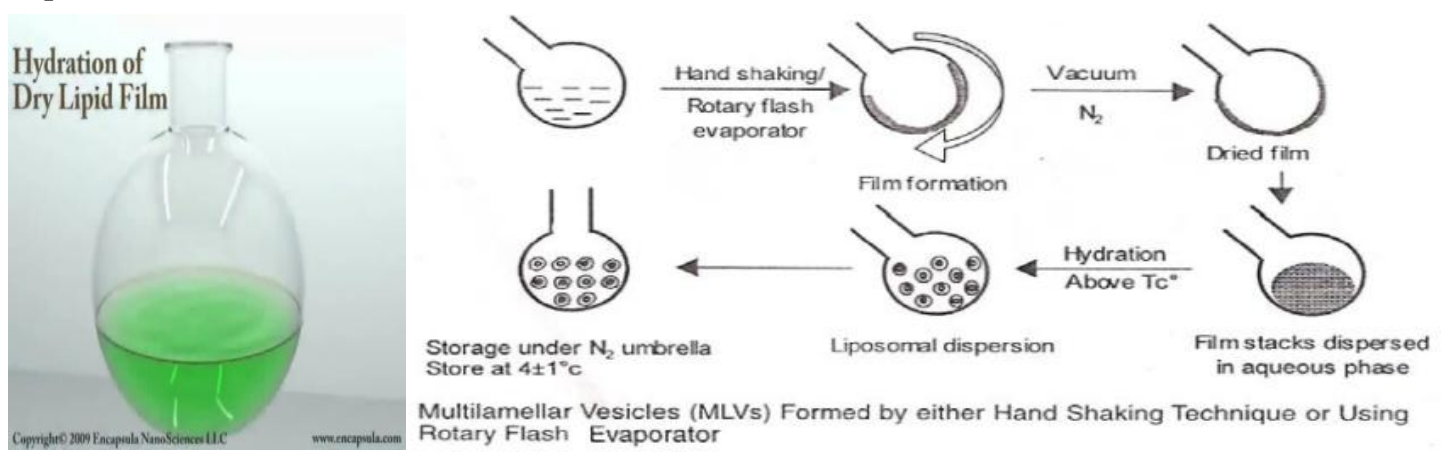

Fig 8: Method of preparation of liposomes by hand shaking and non hand shaking ${ }^{14}$

\section{PROCESS IN MORE DETAIL -}

\section{Step1}

Lipid mixture of different phospholipid and charge components in chloroform :methanol solvent mixture $(2: 1 \mathrm{v} / \mathrm{v})$ is prepared first and then introduced into a round bottom flask with a ground glass neck, This flask is then attached to a rotary evaporator and rotated at $60 \mathrm{rpm}$. The orgnic solvent are evaproted at about 30 degree Celsius or above the transition temperature of the lipids usedThe evaprotor is isolated from the vaccume source by closing the tep.The nitrogen is introduced into the evaporator and the pressure at the cylinder head is gradually raised till there is no difference between inside and out side the flask. The flask is then removed from the evaproter and fixed on to the manifold of lyophilizer to remove residual solvents

\section{Step2-hydration of lipid layer}

After releasing the vacume and removal from the lyophilizer, the flask is flushed with nitrogen, $5 \mathrm{ml}$ of saline phosphate buffer (containing solute to be entrapped )is added.The flask is attached to the evaporator again (flushed with $\mathrm{N}_{2}$ ) and rotated at room

\section{DETERGENT REMOVAL METHODS}

- Detergent

- Dilution

- Reconstituted Sendai virus enveloped vesicles

\section{PHYSICAL DISPERSION OR MECHANICAL DISPERSION METHOD}

Aqueous volume enclosesd usiong this method usually 5$10 \%$, which is very small proportion of total volune used for swelling. Therefore large quantity of water -soluble compound are wasted during sweeling .On the other hand lipid soluble compound $\mathrm{cab}$ be encapsulated to $100 \%$ efficacy, provided they aee not present in quantities that are greater than the structural component of the memberane.

Lipid Film Hydration by hand shaking and non hand shaking:- In this methods, the lipids are casted as stacks of film from their organic solution using 'Flash rotatory evaporator' or 'hand shaking', The film formation will be takes place and the film will be dried in presence of reduced Nitrogen.After the film stacks are dispersed in aqueous phase .Upon hydration the liquid will swell and peel off from wall of round bottom flask and vesiculate forming multi lamellarvesicles(MLVs).Liposomes stored under the nitrogen umbrella store. ${ }^{14,15}$

temperature and pressure at the same speed or below 60 rpm.The lask is left rotating for 30 minutes or unti all lipid has been removed from the wall of the flask and has given homogenous milky -whjite suspension free of visible particles. The suspension is allowed to stand for a further 2 hours at room temperature or at a temperature above the transition temparature of the lipid in order to complete the sweeling process to give MLVs ${ }^{14}$

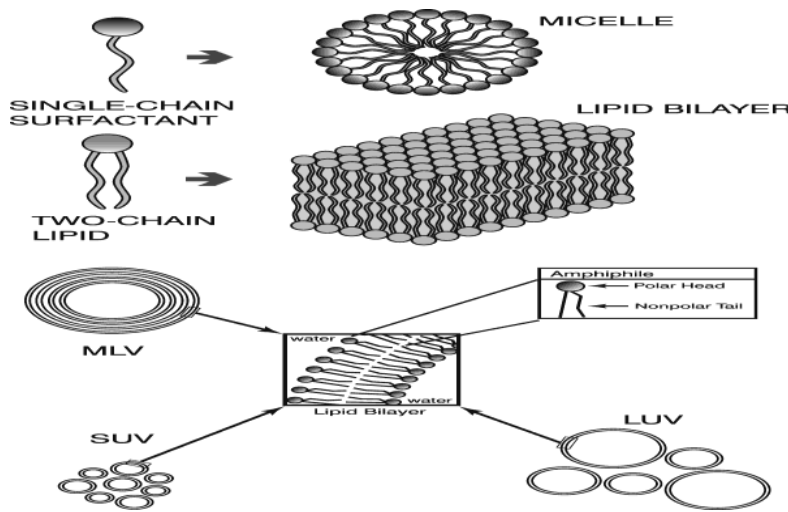

Fig 9: Method of preparation of liposomes by hydration of lipid 


\section{SHAKING VESICLES}

Method described by reeves and dowben in 1996 by which large unicellular vesicles (LUVv) can be formed with higher entrapment volume.The procedure differs from hand shaken method in that it uses a stream of nitrogen to provide agitation rather than the rotationary movements.Solution of lipid in chloroform :methanol mixture is spred over the flat bottom conical flask. The solution is evaproted at room temparature by flow of nitrogen through the flask without disturbing the solutionAfter drying water saturated nitrogen is passed through the flask untill the opacity of the dried film disappears (15-20 mins). After hydration ,lipid is swelled by addition of bulk fluid the flask is inclined to one side , $10-20 \mathrm{ml}$ of 0.2 sucrose in distilled water (degassed)is introduced down the slide of the flask, and the flask is slowly returned to upright orientation. The fluid is allowed to run gently over the lipid layer on the bottom of the flaskThe flask is fluhed with nitrogen ,sealed and allowed to stand for 2 hours at 37 degrees celsius .take care not to disturb the flask in any way.Aftre swelling ,the vesicles are harvested by swirling the contents ,to yield a milky -suspention. ${ }^{14,15,16}$

\section{BUCHI ROTATORY EVAPORATOR NON SHAKING METHOD \& PRO - LIPOSOMES:}

Pro liposomes method devised to increase the surface of dry lipid while keeping the low aqueous volume In this method, the lipid are dried down to finely divided particulate support, such as powered sodium chloride, or sorbitol or other polysacchride-to give proliposomes.The lipid are swelled upon adding water to dried lipid coated powered (pro-liposomes), where the support rapidly dissolves to give a suspention of MLVs in aqueous solution. The size of the carrier influence the size and hetrogeneity of the liposomes.This method overcomes the problem encountered when storing liposomes themselves in either liquid, dry or frozen form , and ois ideally suited for prparation where the material to be entrapped incoropted into lipid membrane,In case where $100 \%$ entrapment of aqueous component is not essential ,this method is also of valve.For preparing pro liposomes a special equipment i.e.buchi rotary evaproter ' R'with water cooled condensor coil and a stainless steel covered thrmocouple connected to a digital thermometer is required.The end of glass solvent inlet tube is modified to a fine point ,so that the solvent is introdused into the flask as a fine spray. ${ }^{14,15,16}$

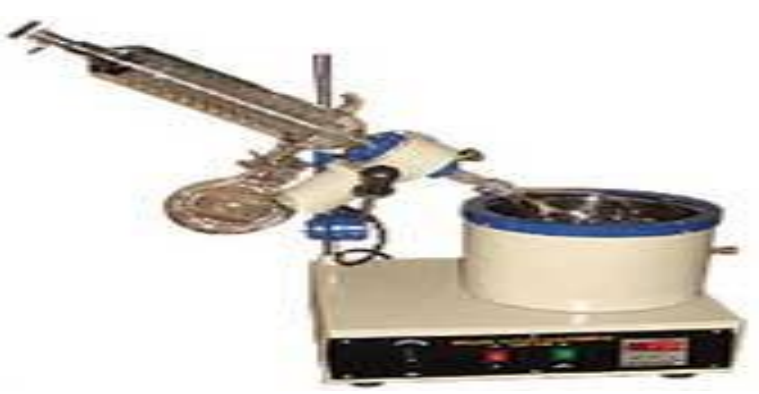

Fig 10: Method of preparation of liposomes by buchi rotatory evaporator

\section{SONICTION:}

This is the method in which Multi lamellar vesicles are transformed to the small uni lamellar vesicles. The ultra sonic irradiation is provided to the MLVs to get the SUVs. There are two methods are used. a) Probe sonication method., b) Bath sonication method.The probe is employed for dispersion, which requires high energy in small volume (e.g. high conc. of lipids or a viscous aqueous phase) while is more suitable for large volumes of diluted liquid Probe tip sonicator provides high energy input to the liquid dispersion but suffer from overheating of liposomal dispersion causing lipid degradation. sonication tip also release titanium into the liposome dispersion which will be removed from the it by centrifugation prior to use. Due to above reason most widely the bath sonicators are used Sonication of MLVs is accomplished by placing dispersion into the the bath sonicator or placing tip fo probe sonicator into the test tube of dispersion.(5-10 min.)After sonication applied the resultant dispersion is centrifuged and according to diagram the SUVs will stay on the top and the small MLVs and aggregated lipids will get settled down. The top layer constitutes pure dispersion of SUVs with varying diameter as size is influenced by composition and concentration, temperature, sonication, volume and sonication tuning. ${ }^{15,16}$

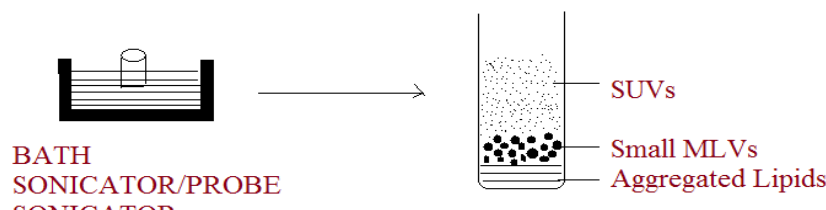

SONICATOR

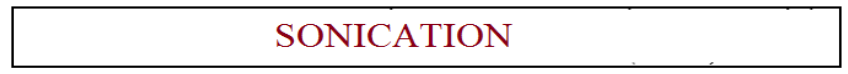

Fig 11: Method of preparation of liposomes by sonicaton

\section{FRECH PRESSURE CELL:}

This method is having the mechanism of high pressure. This method will give the either uni- or oligolamellar liposomes of intermediate size(30-80nm), these liposomes are more stable compared to the sonicated liposomes.This method is having some drawbacks are that initial high cost for the press and the pressure cell liposomes prepared by this method having less structural defects unlike sonicated liposome.$^{16,17}$

\section{MICRO EMULSIFICATION LIPOSOMES:-}

'Micro fluidizer' is used to prepare small MLVs from concentrated Lipid dispersion.Micro fluidizer pumps the fluid at very at very high pressure (10,000 psi), through a 5 micrometer orifice.Then, it is forced along defined micro channels which direct two streams of fluid to collide together at the right angles at a very high velocity, there by affecting an efficient transfer of energy. The lipids can be introduced into the fluidizer, either as large MLVs or as the slurry of un hydrated lipid in organic medium. The fluid collected can be recycled through the the pump and interaction chamber until vesicles of spherical dimensions are obtained. diameter 
After a single pass, the size of vesicles is reduced to a size 0.1 and $0.2 \mathrm{um}$.

\section{MEMBRANE EXTRUSION TECHNIQUE}

The technique can be used to process LUVs as well as MLVs. The size of liposomes is reduced by gently passing them through membrane filter of defined pore size achieved at much lower pressure $(<100 \mathrm{psi})$. In this process, the vesicles contents are exchanged with the dispersion medium during breaking and resealing of phospholipids bilayers as they pass through the polycarbonate membrane. The liposomes produced by this technique have been termed LUVETs. This techniques is most widely used method for SUV and LUV production for in vitro and in vivo studies .

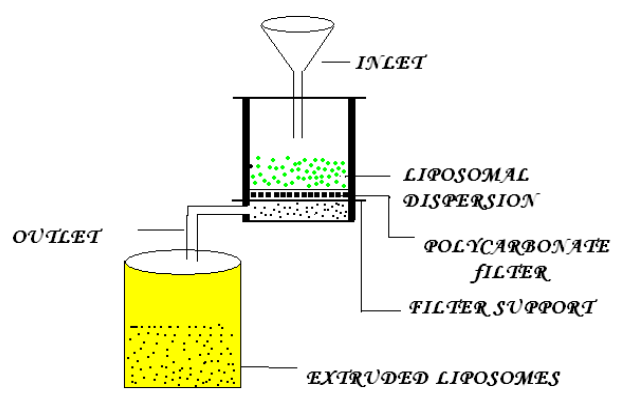

LIPOSOMES PREPARATION USIING EXTRUSION TECHNIQUE
BASED ON POL YCARBONATE FILTERS

Fig 12: Method of preparation of liposomes by sonicaton

DRIED RECONSTITUTED VESICLES (DRVS):-
This method starts with freeze drying of a dispersion of empty SUVs. After freeze drying the freeze dried membrane is obtained.Then these freeze dried SUVs are rehydrated with the use aqueous fluid containing the material to be entrapped. This leads to formation of the solutes in uni- or oligo- lamellar vesicles.

\section{FREEZE THAW SONICATION:}

This method is based upon freezing of a unilamellar dispersion(SUV). Then thawing by standing at room temperature for $15 \mathrm{~min}$.Finally subjecting to a brief Sonication cycle which considerably reduces the permeability of the liposomes membrane. In order to prepare GIANT VESICLES of diameter between 10 and $50 \mathrm{um}$, the freeze thaw technique has been modified to incorporate a dialysis step against hypo- osmolar buffer in the place of sonication. The method is simple, rapid and mild for entrapped solutes, and results in a high proportion of large unilamellar vesicles formation which are useful for study of membrane transport phenomenon.This method is based upon freezing of a unilamellar dispersion(SUV). Then thawing by standing at room temperature for $15 \mathrm{~min}$. Finally subjecting to a brief Sonication cycle which considerably reduces the permeability of the liposomes membrane. In order to prepare GIANT VESICLES of diameter between 10 and 50um, the freeze thaw technique has been modified to incorporate a dialysis step against hypo- osmolar buffer in the place of sonication. The method is simple, rapid and mild for entrapped solutes, and results in a high proportion of large unilamellar vesicles formation which are useful for study of membrane transport phenomenon. ${ }^{15,16,17}$

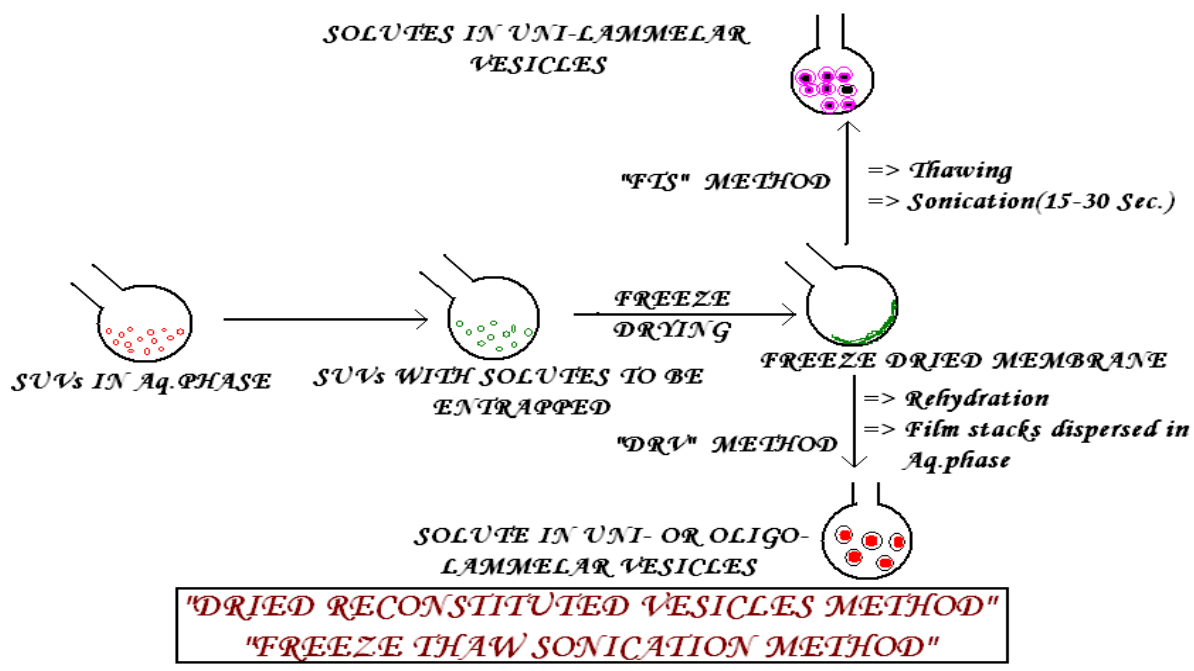

Fig 13: Method of preparation of liposomes by freeze thaw sonication

\section{PH INDUCED VESICULATION}

this method prepaer ULVs from MLVs without sonication or high pressure application ,they are reassembled by simply charging the ph it is an electrostatic phenomenon, the transfering chage in $\mathrm{PH}$ bring about an increase in the surface charge density of lipid bilayer ,provided this exceeeds a certain threshold valve of around $1-2 \mathrm{uc} / \mathrm{cm}^{2}$, spontanous vesiculation will occur the period of exposure of the phospholipid to high ph is less than $2 \mathrm{~min} s$ and not long enough to cause detectable degratation of phospholipd.In this method ,dry film of lipid is obtained is the round bottom flask usin the rotatory evaporator and last traces of the solvent are removed using freeze dryer.Then,the film is hydrated with minimum quantity of water by hand shaking at room temperature. At this stage material to be entrapped inside the vesicles may be added in the water before adddition to the lipid.The dispersion is completed by 
subjecting the suspention to six freeze thawing cycle between 15 degree cesilsius and 5 degrees celsius.the PH of the despersion will be 2.5-3Sodium hydroxide solution $(1 \mathrm{~m})$ is added rapidly with mmixing into the suspension then then the $\mathrm{PH}$ is redused by addition of $0.1 \mathrm{~m} \mathrm{hcl}$ until a valve of PH 7.5 is achieved. ${ }^{17,18}$

\section{CALCIUM INDUSED FUSION -}

It uses concept of aggregation and fusion of acid phospholipid vesicles in the presence of calcium .In this method ,lipid is dried down and suspended in sonication buffer (Nacl 0.385g,histidin $31.0 \mathrm{mg}$, this -base $24.2 \mathrm{mg}$ ,water 100ml ,PH 7.4)The large liposomes and lipid particles are removed by centrifugation at $100,000 \mathrm{~g}$.Equimolar proportion of calcium solution precipite is formed It is incubeted for 60 mins at 37 degree celsius and the precipitate is separated by spinning the container at $3000 \mathrm{~g}$ for $2 \mathrm{o} \mathrm{min} \mathrm{at} \mathrm{room}$ temperature the supleemantant is dscarded.The pellet is resuspended is buffered saline containing the material to be entraped and incubated at 37 degrees celsius for 10 min The EDTA $(170 \mathrm{~mm})$ is added in buffer with mixing The cloudy precipite will clear rapidly, then incubate for $15 \mathrm{~min}$ at 37 degree celsius and further $15 \mathrm{~min} \mathrm{mix}$ at room temparature.Finally, the ca/EDTA complex is removed by dialysing again a litre of buffer. ${ }^{18,19}$

\section{SOLVENT DISPERSION TECHNIQUES}

Ether and Ethanol Injection:-

The method involves the extrusion of MLV at 20,000 psi at $4^{\circ} \mathrm{C}$ through a small orifice. The method has several advantages over sonication method. The method is simple rapid, reproducible and involves gentle handling of unstable materials (Hamilton and Guo, 1984). ${ }^{17}$, ${ }^{18}$ Ethanol Injection Method A lipid solution of ethanol is rapidly injected to a vast excess of buffer. The MLVsare immediately formed. The drawbacks of the method are that the population is heterogeneous (30-110 nm), liposomes are very dilute, it is difficult to remove all ethanol because it forms azeotrope with water and the possibility of various biologically active macromolecules to inactivation in the presence of even low amounts of ethanol (Batzri and Korn, 1973). ${ }^{16}$

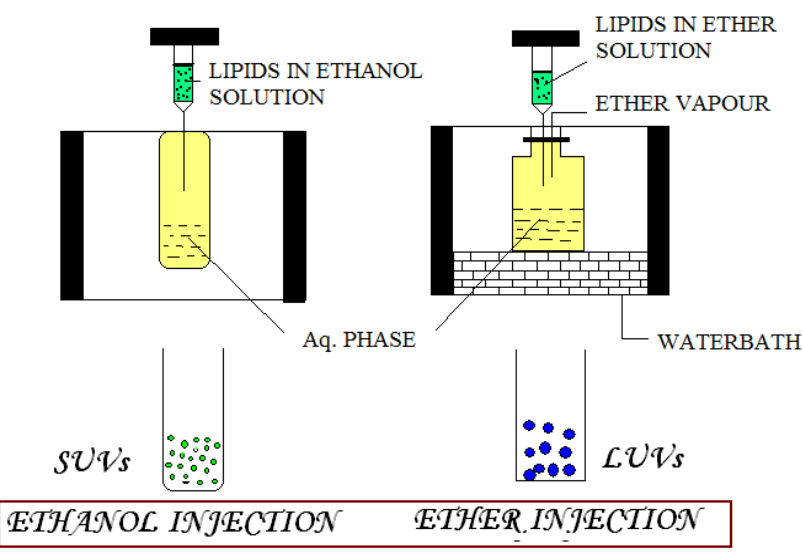

Fig 14: Method of preparation of liposome's by solvent dispersion techniques

\section{Double Emulsion Vesicles:-}

In this method, the outer half of the liposome membrane is created at a second interphase between two phases by emulsification of an organic solution in water.If the organic solution, which already contains water droplet, is introduced into excess aqueous medium followed by mechanical dispersion, multi compartment vesicles are obtained. The ordered dispersion so obtained is described as $\mathrm{W} / \mathrm{O} / \mathrm{W}$ system. If the organic solution, which already contains water droplet, is introduced into excess aqueous medium followed by mechanical dispersion, multi compartment vesicles are obtained. The ordered dispersion so obtained is described as W/O/W system. At this step monolayers of phospholipids surrounding each water compartment are closely opposed by each other. The next step is to bring about the collapse of a certain proportion of the water droplets by vigorous shaking by using mechanical vortex mixer.Then the lipid monolayer which enclosed the collapsed vesicle is contributed to adjacent intact vesicle to form the outer leaflet of bilayer of large unilamellar liposomes. The vesicles formed are unilamellar and are having diameter of 0.5 micrometer. The encapsulation is found to be $50 \%$. $16,17,18,19$

\section{REVERSE PHASE EVAPORATION VESICLES:}

Sonicated methods (stable plurilamellar vesicles -SPVs) in this method,w/o dispersion is prepared as described earlier with excess lipid, but drying process is accompanined by continued bath sonication with a stream of nitrogen.The redistribution and equilibration of aqueous solvent and solute occur this time in between the various bilayer in each plurilamellar vesicles The internal structure of SPVs is different from that of MLV-REV,in that they lack a large aqueous medium being located in compartment in between adjucent lamellae.the percent entrapment is normally $30 \% 18$

\section{DETERGENT REMOVAL METHODS}

Detergent/Phospholipids mixtures can form large unilamellar vesicles upon removal of non ionic detergent using appropriate adsorbents for the detergent. in this method, the phospholipid are brought into intimate contact with the aqueous phase via the intermediary of detergent, which associated with phospholipid molucule from water,In structural formed as a result of this associated are known as micelles , and can be composed of several hundred component molecules. Their shape and size depend on chemical nature of the detergent ,the concentration and other lipid involved.The concentrated of detergent in water at which micelles from is known as critical micelle concentration(CMC). ${ }^{18,19}$

\section{REMOTE OR ACTIVE LOADIND}

The membrane from lipid bilayer is in general impermeable to ions and larger hydrophilic molecules Ion transport can be regulated by the ionophores while permeation of neutral and weakly hydrophobic moleculescan be controlled by c oncentration gradients. Some weak acids or bases howeve $r$, can be transported through the membrane due to various trans membrane gradients, such as electrical, ionic $(\mathrm{pH})$ or specific salt(ch emical potential) gradiens

Several 
methods exist for improved loading of the drugs, includi ng remote (active) loading methods which load drug molecules into preformed liposomes using $\mathrm{pH}$ gradients and potential difference across liposomal membranesActive loading techniques are having following advantages over passive loading
techniques.A high encapsulation efficiency and capacity. A reduced leakage of encapsulated compounds 'Bed Side' loading of drugs thus loss of retention of drugs by diffusion or chemical degradation during storage. Reduction in hazards. ${ }^{19,20,21}$

\section{CHARACTERIZATION}

\begin{tabular}{|l|l|}
\hline Characterization parameters & Analytical method/Instrument \\
\hline Vesicle shape and surface morphology & $\begin{array}{l}\text { Transmission electron microscopy, } \\
\text { Freeze-fracture electron microscopy }\end{array}$ \\
\hline $\begin{array}{l}\text { Mean vesicle size and size distribution } \\
\text { submicron and micron range) }\end{array}$ & $\begin{array}{l}\text { Dynamic light scattering, zetasizer, } \\
\text { Photon correlation spectroscopy, laser light scattering, gel permeation } \\
\text { and gel exclusion }\end{array}$ \\
\hline Surface charge & Free-flow electrophoresis \\
\hline Electrical surface potential and surface Ph & Zetapotential measurements \& pH sensitive probes \\
\hline Lamellarity & $\begin{array}{l}\text { Small angle X-ray scattering, 31P-NMR, Freeze-fracture electron } \\
\text { microscopy }\end{array}$ \\
\hline Phase behavior & Freeze-fracture electron microscopy, Differential scanning colorimetery \\
\hline Percent of free drug/ percent capture & $\begin{array}{l}\text { Minicolumn centrifugation, ion-exchange chromatography, } \\
\text { radiolabelling }\end{array}$ \\
\hline
\end{tabular}

Table 1: Physical characterization of liposomes

\section{CHEMICAL CHARACTERIZATION}

\begin{tabular}{|l|l|}
\hline Characterization parameters & Analytical method/Instrument \\
\hline Phospholipid concentration & Barlett assay, stewart assay, HPLC \\
\hline Cholesterol concentration & Cholesterol oxidase assay and HPLC \\
\hline Phopholipid peroxidation & UV absorbance, Iodometric and GLC \\
\hline
\end{tabular}

Table 2: Chemical characterization of liposomes

\section{BIOLOGICAL CHARACTERIZATION}

\begin{tabular}{|l|l|}
\hline Characterization parameters & Analytical method/Instrument \\
\hline Sterility & Aerobic or anaerobic cultures \\
\hline Pyrogenicity & Limulus Amebocyte Lysate (LAL) test \\
\hline Animal toxicity & Monitoring survival rates, histology and pathology \\
\hline
\end{tabular}

Table 3: Biological characterization of liposomes

\section{PHYSICAL CHARACTERIZATION}

\section{SIZE AND ITS DISTRIBUTION}

Most precise method to determine size of the liposome is by electron microscopy, since it allows to view each individual liposome and to obtain exact information about the profile of liposome population over the whole range of sizes. Unfortunately it is very time consuming and requires equipments thatmay not always be immediately available to hand .In contrast, laser light scattering (quasi-elastic laser light scattering) method is very simple and rapid to perform but having disadvantage of measuring an average property of the bulk of the liposomes. $^{21,22}$

\section{MICROSCOPIC METHODS}

Light microscopy

has been utilized to examine the gross size/distribution o f large vesicles produced from single chain amphiphilesIf the bilayers are having fluorescent hydrophilic probes, the liposomes can be examined under a fluorescent microscope. The resolution of the light microscope limits this technique for obtaining of the preparation. electron microscopy, one can obtain an estimate of the lower end of the size distribution.For the large vesi cles (5um), negative stain electron microscopy is not suitable for determination of the size distribution be cause vesicle distortion during preparation of the specimen makes it difficult to obtain an estimate of the diameter of the original particle. A technical difficulty in obtaining good negativestains of liposomes is the spreading of thevesicles 
on the carbon-coated

grid.Treating the grid with $0.1 \mathrm{mg} / \mathrm{mL}$ solution of bacitracinor coating the support films with silica by the evaporation

of silicon monoxide, usually permits a satisfactory sprea ding of liposomes for negative staining. Glow discharging of the grids immediately priorto use is of considerable help to the spreading of liposomes on the grid surface.

Freeze etch and freeze fracture electron microscopy techniques have been used to study vesicle size and structure. $^{21,22,23}$

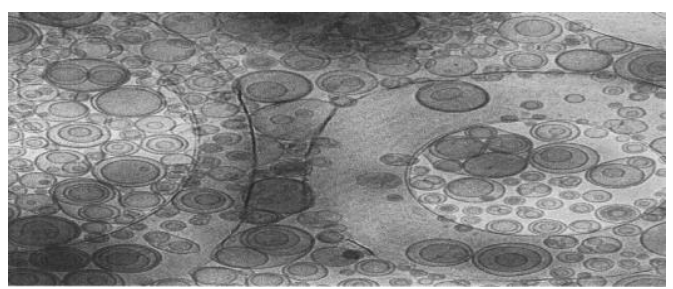

Fig 15: Structure of liposomes by microscopic methods

\section{GEL PERMEATION}

Exclusion chromatography on large pure gels was introduced to separate SUVs from radial MLVs.However, large vesicles of 1-3 um diameter usuall $y$ failto enter the gel and are retained on the top of the column.A thin layer chromatography system using agaro se beads has been introduced as a convenient, fast technique for obtaining a rough estimation of the size distribution of a liposomes preparation. However, it was not reported if this procedure was sensitive to a physical blockage of the pores of the agarose gel as is the more conventional column chromatography.

\section{B) SURFACE CHARGE}

A method using free flow electrophoresis is used to dete rmine the surface charge of MLVs, A technique has been developed that separates extruded ves icles on the basis of their surface charge by electrophoresis on a cellulose acetate plate in a sodium borate buffer pH 8.8. The lipid samples ( 5 nmoles) are applied to the plate and electrophoresisis carried out at

degrees Celsiuson a flat bed apparatus for 30 mins at 18 $\mathrm{V} / \mathrm{cm}$. The plate is dried and the phospholipids are visuali zed by the molybdenum blue reagent. Liposomes upto 0.2 um in diameter can migrate on this support and with this technique as little as 2 mole $\%$ of charged lipids can be detected in a liposome bilayer. This sensitive assay should prove valuable for examining the charge heterogeneity in liposome preparation for following fusion between two populations of vesicles with different charge and for determining.

\section{C) PERCENT CAPTURE (ENTRAPMENT)}

It is essential to measure the quantity of material entrapp ed in side liposomes before the study of behavior of this entrapped material in physical and biological systems, since the effects observed experimentally will usually be dose related. After removal of un incorporated material by the separation techniques, one may assume that the quantity of material remaining

is $100 \%$ entrapped, but the preparation may change

upon storage. For long term stability test and for developing new liposome formulation or method of preparation, a technique is needed for separating free from entrapped material. ${ }^{22,23,24}$

\section{MINI COLUMN CENTRIFUGATION METHOD}

In this method, the hydrated gel (sephadexG-50) is filled in a barrel of $1 \mathrm{~mL}$ syringe without plunger which is plugged with a whatman GF/B filter pad. This barrel is rested in a centrifuge tube. This tube is spun at $2000 \mathrm{rpm}$ for $3 \mathrm{mins}$ to remove excess saline solution fromthe gel. After centrifugation the gel column should be dried and have come away from the side of the barrel Then, eluted saline is removed from the collection tube.Liposome suspension $(0.2 \mathrm{~mL}$ undiluted) is applied drop wise to the top of the gel bed, and the column is spun at $2000 \mathrm{rpm}$ for $3 \mathrm{~min}$. to expel the void volume containing the liposomes into the centrifuge tube.The elute is then removed and set a side for assay. ${ }^{23,24,25}$

\section{D)ENTRAPPED VOLUME}

The entrapped volume of a population of liposomes (inu $\mathrm{L} / \mathrm{mg}$ phospholipid) can often be reduced from measurements of the total quantity of solute entrapped in side liposomes assuring that the concentration of solute

in the aqueous medium inside liposomes is the same as that in the solution used to start with, and assuming that no solute has leaked out of the liposomes after separation from unentrapped material.However, in many cases such assumption is invalid. For e.g.,in two phase methods of preparation, water can be lost from the internal compartment during the drying step to remove organic solvent. ${ }^{25,26,27}$

down

\section{E) LAMELLARITY}

The average number of bilayers present in a liposome can be found by freeze electron microscopy and by $31 \mathrm{P}-\mathrm{NMR}$.In the latter technique, the signals are

recorded before and after the addition of broadening agent such as manganese ions which inteact with the outer leaflet of the outer most bilayers. Thus, a $50 \%$ reduction in NMR signal means that the liposome preparation is unilamellar and a $25 \%$ reduction in the intensity of the original NMR signal means that there are 2 bilayers in the liposom Nowadays, freeze fracturing electron microscopy hasbecome a very popular methd to study str uctural details of aqueous lipid dispersions. Phase Behavior of Liposomes An important feature of lipid membrane is the existence of a temperature dependant, reversible phase transition, where the hydrocarbon chains of the phospholipid undergo a transformation from an ordered (gel) state to a more disordered fluid (liquid crystalline) state.These change have been documented by freeze fracture electronmicroscopy, but most easily de monstrated by differential scanning calorimetery. 
The physical state of the bilayers pro foundly affects the permeability, leakage rates and overall stability of the liposomes. The phase transition temperature (Tc) is a function of phospholipid content of the bilayers. The Tc can give good clues regarding liposomal stability, permeability and whether drug is entrapped in the bilayer $\mathrm{s}$ or the aqueous compartment.

\section{DRUG RELEASE}

The mechanism of drug release from the liposomes can $b$ eassessed by the use of a well calibrated in vitro diffusio $\mathrm{n}$

cell.The liposome based formulations can be assisted by employing in vitro assays to predict pharmacokinetics and bioavailability of the drug before employing costly and time-consuming in vivo studies. The dilution-induced drug release in buffer and plasma was employed as predictor for pharmacokinetic performance of liposomal formulations and another assay which determined intracellular drug release induced by liposomes degradation in the presence of mouse-liver lysosome lysate was used to assess the bioavailability of the drug. ${ }^{28,29,30}$

\section{CHEMICAL CHARACTERIZATION}

\section{A) QUANTITATIVE DETERMINATION OF PHOSPHOLIPIDS}

It is difficult to measure directly the phospholipid concentration, since dried lipids can often contain considerable quantities of residual solvent. Consequently the method most widely used for determination of phospholipidis an indirect one in which the phosphate content of the sample is first measured, The phospholipids are measured either using Bartlett assay or Stewart Assay . ${ }^{29,30,31}$

\section{Bartlett Assay}

In the Bartlett assay the phospholipid phosphorous in the sample is first hydrolyzed to inorganic phosphate. This is converted to phospho-molybdic acid by the addition ammonium molybdate and phospho-molybdic acid is quantitatively to a blue colored compound by amino- naphthyl- sulfonic acid. The intensity of the blue color is measured spectrophotometrically and is compared with the curve of standards to give phosphorous and hence phosphorlipid content Bartlett assay is very sensitive but is not reasonably reproducible. The problem is that the test is easily upset by trace contamination with inorganic phosphate. Therefore, precaution is to be taken using a set of borosilicate glass tubes

which are

washed well and not usedfor any other purpose.Use of double-distille $\mathrm{d}$ water for making up solutions. The sensitivity of the $\mathrm{Ba}$ rtlett assay to inorganic phosphate creates problem with measurement of phospholipid liposomes suspended in physiological buffers, which usually contain phosphate ions. This can beovercome by employ ing a more specific method which Is unaffected by inorganic phosphate. ${ }^{32,33}$

\section{STEWART ASSAY}

In Stewart assay, the phospholipid forms a complex with ammonium ferrothiocyanate in organic solution. The advantage of this method is that the presen ce ofinorganic phosphate does not interfere with the assa y.This method is not applicable to samples where mixture of unknown phospholipids may be present.In this method, the standar $\mathrm{d}$ curve is first prepared byadding ammonium ferrothiocy anate $(0.1 \mathrm{M})$ solution with different known concentrations of phospholipids in chloro form. Similarly, the samples are treated and optical density of these solutions is measured at $485 \mathrm{~nm}$ the absorbance of samples compared with the standard curve of phospholipids to get the concentration.

\section{B) PHOSPHOLIPIDS OXIDATION}

Oxidation of the fatty acids of phospholipids in the abse nceof specific oxidants occurs via a free radical chain mechanism. The initiation step is abstraction of a hydrogen atom from the

lipid chain that can occur most commonly as a result ofe xposure to electro-magnetic radiation or trace amount of contamination with the transition metal ions.

Polychain-saturated

lipids are particularly prone toxidative degradation.A nu mber of techniques are available for determining the oxidation of phospholipids at different stages i.e., UVabsorbance

method, TBA method (for endoperoxides), iodometric method (for hydroperoxides) and GLC method. ${ }^{33,34,35}$

\section{C) CHOLESTEROL ANALYSIS}

Cholesterol is qualitatively analyzed using capillary column of flexible fused silica where as it is quantitatively estimated (in therange of 0-8ug) by measur ing the absorbance of purple complex produced with iron upon

reaction with a combined reagent containing ferric per chlorate, ethyl acetate and sulfuric acid at 610nm. ${ }^{36,37}$ 
APPLICATION

\begin{tabular}{|c|c|}
\hline Application & Utilized \\
\hline $\begin{array}{l}\text { Liposomes in } \\
\text { bioengineering }\end{array}$ & $\begin{array}{l}\text { Modern genetic engineering and gene recombinant technology is based on the deliveryof } \\
\text { genetic material, i.e. fragments of DNA, into various cells and microorganismsin order to alter } \\
\text { their genetic code and force them to produce particular proteins or } \\
\text { Polypeptides }\end{array}$ \\
\hline $\begin{array}{l}\text { Medical applications } \\
\text { of stealth liposomes }\end{array}$ & $\begin{array}{l}\text { Sterically stabilised vesicles can act either as long circulating microreservoirs or tumour } \\
\text { (or site of inflammation and infection) targetting vehicles. The former application srequires } \\
\text { larger liposomes }\left({ }_{-} 0.2 \_\mathrm{m} \text { ) while the latter one is due to the ability of small vesicles to leave }\right. \\
\text { the blood circulation }\end{array}$ \\
\hline $\begin{array}{l}\text { Liposomes in } \\
\text { anticancer therap }\end{array}$ & $\begin{array}{l}\text { These cells are in tumours, but also in gastrointestinal mucosa, hair, and blood cells and } \\
\text { therefore this class of drugs are very toxic. The most used andstudied is Adriamycin } \\
\text { (commercial name for Doxorubicin } \mathrm{HCl} \text { ). }\end{array}$ \\
\hline $\begin{array}{l}\text { Macrophage } \\
\text { activation and } \\
\text { vaccination }\end{array}$ & $\begin{array}{l}\text { The automatic targetting of liposomes to macrophages can be exploited in several } \\
\text { other ways, including the macrophage activation and in vaccination }\end{array}$ \\
\hline $\begin{array}{l}\text { Liposomes in } \\
\text { parasitic diseases and } \\
\text { infections }\end{array}$ & $\begin{array}{l}\text { Since conventional liposomes are digested by phagocytic cells in the body after intravenous } \\
\text { administration, they are ideal vehicles for the targetting of drug molecules } \\
\text { into these macrophages }\end{array}$ \\
\hline $\begin{array}{l}\text { Applications of } \\
\text { liposomes in basic } \\
\text { sciences }\end{array}$ & $\begin{array}{l}\text { Lipid membranes are two dimensional surfaces floating in three dimensional space.In the } \\
\text { simplest models, they can be characterised only by their flexibility which is related to their } \\
\text { bending elasticity. }\end{array}$ \\
\hline $\begin{array}{l}\text { Application of } \\
\text { liposomes in agro- } \\
\text { food industry }\end{array}$ & $\begin{array}{l}\text { The ability of liposomes to solubilize compounds with demanding solubility properties, } \\
\text { sequester compounds from potentially harmful milieu, and release incorporated molecules in a } \\
\text { sustained and predictable fashion can be used also in the food processing industry For instance, } \\
\text { lecithin and some other polar lipids are routinely extracted from nutrients, such as egg yolks or } \\
\text { soya beans }{ }^{.0,41}\end{array}$ \\
\hline
\end{tabular}

Table 4: Application of Liposomes

\begin{tabular}{|l|l|l|}
\hline Liposome Utility & Current Applications & Disease States Treated \\
\hline Solubilization & Amphotericin B, minoxidil & Fungal infections \\
\hline Site-Avoidance & $\begin{array}{l}\text { Amphotericin B - reduced nephrotoxicity, Fungal infections, } \\
\text { cancer doxorubicin - decreased cardiotoxicity }\end{array}$ & Fungal infections \\
\hline Sustained-Release & $\begin{array}{l}\text { Systemic antineoplastic drugs, hormones, Cancer, } \\
\text { biotherapeutics corticosteroids, drug depot in the lungs }\end{array}$ & Cancer, biotherapeutics \\
\hline Drug protection & Cytosine arabinoside, interleukins & Cancer, etc. \\
\hline RES Targeting & $\begin{array}{l}\text { Immunomodulators, vaccines, antimalarials, Cancer, MAI, } \\
\text { tropical parasites macophage-located diseases }\end{array}$ & Cancer, MAI, tropical \\
\hline Specific Targeting & Cells bearing specific antigens & Wide therapeutic \\
\hline Accumulation & Prostaglandins & Cardiovascular diseases \\
\hline
\end{tabular}

Table 5: Liposomes in the pharmaceutical industry

\begin{tabular}{|l|l|l|}
\hline Product & Manufacturer & Liposomes and key ingredients \\
\hline Efect du Soleil & L'Or'eal & Tanning agents in liposomes Niosomes Lancome \\
\hline Niosomes & Lancome (L'Or'eal) & Glyceropolyether with moisturizers \\
\hline Nactosomes & Lancome (L'Or'eal & Vitamins \\
\hline Formule Liposome Gel & Payot (Ferdinand Muehlens) & Thymoxin, hyaluronic acid \\
\hline Future Perfect Skin Gel & Estee Lauder & $\begin{array}{l}\text { TMF, vitamins E, A palmitate, cerebroside ceramide, } \\
\text { phospholipid }\end{array}$ \\
\hline Symphatic 2000 & Biopharm GmbH & Thymus extract, vitamin A palmitate \\
\hline Natipide II & Nattermann PL & Liposomal gel for do-it-yourself \\
\hline Flawless finish & Elizabeth Arden & Liquid make-up \\
\hline Inovita & Pharm/Apotheke & Thymus extract, hyaluronic \\
\hline Eye Perfector & Avon & Soothing cream to reduce eye \\
\hline
\end{tabular}

Table 6: Some liposomal cosmetic formulations currently on the market ${ }^{48,49,50}$ 


\begin{tabular}{|l|l|l|l|}
\hline Marketed product & Drug used & Target diseases & Company \\
\hline $\begin{array}{l}\text { DoxilTM or } \\
\text { CaelyxTM }\end{array}$ & Doxorubicin & Kaposi’s sarcoma & SEQUUS, USA \\
\hline DaunoXomeTM & $\begin{array}{l}\text { DaunSolid } \\
\text { tumoursorubicin }\end{array}$ & $\begin{array}{l}\text { Kaposi's sarcoma, breast \& lung } \\
\text { cancer }\end{array}$ & NeXstar, USA \\
\hline AmphotecTM & Amphotericin-B & fungal infections, Leishmaniasis & SEQUUS, USA \\
\hline Fungizone® & Amphotericin-B & fungal infections, Leishmaniasis & Bristol-squibb, Netherland \\
\hline VENTUSTM & Prostaglandin-E1 & Systemic inflammatory diseases & The liposome company, USA \\
\hline ALECTM & $\begin{array}{l}\text { Dry protein free } \\
\text { powder of DPPC-PG }\end{array}$ & Expanding lung diseases in babies & Britannia Pharm, UK \\
\hline Topex-Br & Terbutaline sulphate & Asthma & Ozone, USA \\
\hline Depocyt & Cytarabine & Cancer therapy & Skye Pharm, USA \\
\hline Novasome ${ }^{\text {Nand }}$ & Smallpox vaccine & Smallpox & Novavax, USA \\
\hline $\begin{array}{l}\text { Avian retrovirus } \\
\text { vaccine }\end{array}$ & Killed avian retrovirus & Chicken pox & Vineland lab, USA \\
\hline Doxil® & Doxorubicin Hcl & Refractory ovarian cancer & ALZA, USA \\
\hline EvacetTM & Doxorubicin & Metastatic breast cancer & The liposome company, USA \\
\hline
\end{tabular}

\section{Table 7: list of marketed products}

\section{WORLD MARKET OF LIPOSOMES:}

The liposomes are among the drug carrier being extensively used today. This category of drug delivery system has occupied a major area in the world market. There is no place in the world left where liposomes have not been marketed. Among the major areas Western Europe with $13 \%$ of the total market dominates followed by North America and South Asia with contribution of $12 \%$ and $11 \%$ respectively.

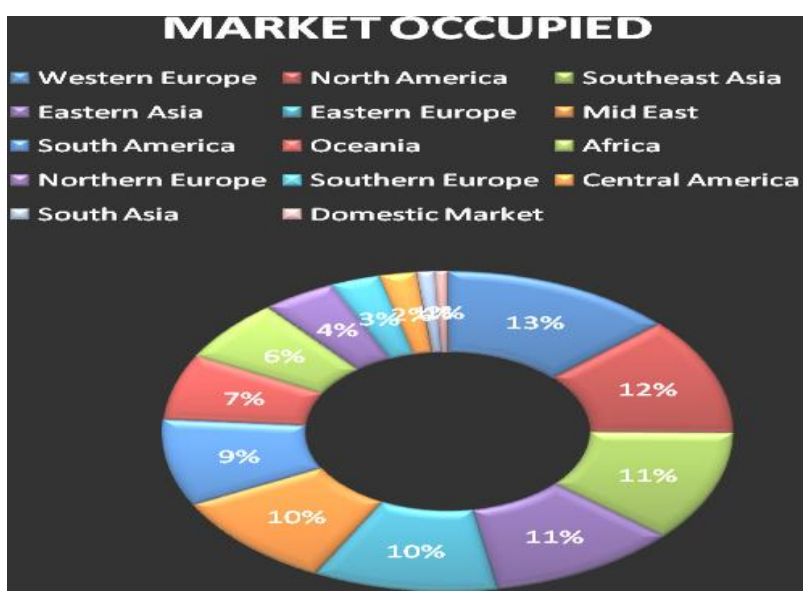

Fig 16: Representing the world market share of Liposome Business ${ }^{53,54}$

\section{REFERENCE}

1) NanopharmaceuticalsNanopharmaceuticals.Org..2005-2006:12. Http://Www.Nanopharmaceuticals.Org/Liposomes

2) Jain Sanjay K And Jain N.K Controlled And Novel Drug Delivery Systems, Chapter 15 Liposomes As Drug Carriers,2005: 2-12

3) Torchilin V P. Recent Advances With Liposomes As Pharmaceutical

Carriers,

Www.Ncbi.Nlm.Nih.Gov/Pubmed/15688077:1

4) Riaz Mohammad ,Liposomes Preparation Methods" Pakistan Journal of Pharmaceutical Sciences Vol.19(1), January 1996, 65-77

5) Lasic D.D. Application of Liposomes, Handbook Of Biological Physics ,Volume 1,Elsevier Science,1995:1-519.

6) Barani, H. \& Montazer, M. "A Review on Applications of Liposomes in Textile Processing.Journal of Liposome Research, 2008, 18, 249-262.

7) http.www nanolifeneutra .com liposomes

8) Kumar Ajay, Kamble Badde Shital , Varsha B. Pokharkar Development And Characterization Of Liposomes And Drug Delivery System For Nimesulides ,International Journal Of Pharmacy And Pharmaceutical Sciences.

9) Www.News-Medical.Net/Health/What-Is-A-Liposome.Aspx, What Is A Liposome? - From News-Medical.Net.

10) Dosi Abha Created By Mehta Akul Www Pharmaxexchange Info...Author Acer Flexible Liposomes For Topical Applications In Cosmetics Blume Gabriele. 
11) Satynarayna U, Biochemistry, 3rd Edition Published By Arunabha Sen Book And Allid (P) Ltd First Published 2008: 35 .

12) Cabral E. C. M., Zollner R. L. And Santana M. H. A. Brazilian Journal of Chemical Engineering Preparation And Characterization Of Liposmes Entrapping Allergenic Protein Received: February 13, 2003003.

13) Bangham, A.D. and R.W. Horne, 1964, Negative staining of phospholipids and their structured by surface active agents as observed in the electron microscope, J. Mol. Biol. 8,660-668.

14) Www.Dr-Baumann-International.

15) Riaz Mohammad, Review Liposomes Preparation Method Pakistan Journal of Pharmaceutical Sciences Vol.19(1), January 1996:65-77.

16) Deepak,By Preparation of Liposomes Www.Google .Com.

17) Xiaoling Li,Bhaskara R.Jasti ,Mcgram-Hill,Chemical Enginerring ,Design Of Controlled Release Drug Delivery System.,Page No 65,367

18) Rajan K. Verma and Sanjay Garg, "Current Status of Drug Delivery Technologies And Future Directions," Pharmaceutical Technology On-Line, 25 (2), 1-14 (2001).

19) Dwivedi Chandraprakash, Verma , Review On Preparation And Characterization of Liposomes With Application, Journal Of Scientific \& Innovative Research, Volume 2 Issue 2 Issn: 2230-4818:1-31.

20) Bhatia A , Kumar R, \& Katare O.P. Tamoxifen In Topical Liposomes: Development, Characterization And In-Vitro Evaluation. J. Pharm. Pharmaceut. Sci., 7(2), 2004:252-259.

21) Vyas S.P \& Khartarget R. K. \& Controlled Drug Delivery Novelcarrier Systems ,Reprinted In 2007,Page No 177-242.

22) Laouini A., Jaafar-Maalej C., Preparation, Characterization And Applications of Liposomes: State of The Art, Copyright $(\odot$ 2012 American Scientific Publishers, Journal of Colloid Science And Biotechnology Vol. 1, 147-168, 2012:1-22

23) Chatterjee Subroto, Banerjee Dipak K., Preparation, Isolation, And Characterization Of Liposomes Containing Natural And Synthetic Lipids, Link.Springer.Com,Pg.No 1-2.

24) Vemuri S, Rhodes Ct., Preparation And Characterization of Liposomes As Therapeutic Delivery Systems: A Review, Pharm Acta Helv. 1995 Jul; 70(2):95-111.

25) Jean M.M, Gary R.M., Lynn E.S, And Carl R.A. "Oil In Water Liposomal Emulsions: Characterization And Potential Use In Vaccine Delivery", Journal Of Pharmaceutical Sciences, Vol 88 , No $2: 1332-1339$.

26) Hupfeld Stefan, Size Characterisation Of Liposomes Using Asymmetrical Flow Field-Flow Fractionation Factors Influencing Fractionation And Size Determination, University Of Troms $\varnothing$ Faculty Of Medicine Department Of Pharmacy August 2009:1-91

27) Cabral E. C. M. , Zollner R. L. And Santana M. H. A., Preparation And Characterization Of Liposomes Entrapping Allergenic Proteins, Brazilian Journal Of Chemical Engineering, Vol. 21, No. 02 Pp. 137 - 146, April - June 2004:1-10.

28) Chetanachan P., Akarachalanon P. , Ultrastructural Characterization of Liposomes Using Transmission Electron Microscope,Http://Www.Scientific.Net Trans Tech Publications, Switzerland, Advanced Materials Research Vols. 55-57 (2008): 709-711.

29) Franzen Ulrik, Vermehren Charlotte, Physicochemical Characterization of A Pegylated Liposomal Drug Formulation Using Capillary Electrophoresis, Wiley-Vch Verlag Gmbh \& Co. Kgaa, Weinheim Www.Electrophoresis-Journal.Com, Electrophoresis 2011:1-11

30) Barani, H. \& Montazer, M. "A Review on Applications of Liposomes In Textile Processing. Journal Of Liposome Research,” 2008, 18, 249-262
31) Liposome Related Protocols- Chemical Analysis Of Liposomal Components (Bartlett Assay) Encapsula Nanosciences January 3: 2009

32) Banerjee R, Liposomes: Applications In Medicine, J Biomater Appl. $2001 \quad$ Jul;16(1):3-21. Http://Www.Ncbi.Nlm.Nih.Gov/Pubmed

33) Dan D. Lasic, Novel Applications of Liposomes, Elsevier Science Ltd.volume 16,Tibtech July 1998 :307-321.

34) Vladimir P. Torchilin, Recent Advances With Liposomes As Pharmaceutical Carriers, Www.Nature.Com/Reviews/Drugdisc, February 2005volume 4:145-160

35) Dua J S , Rana A C ,Bhandari A K, Liposome: Methods Of Preparation And Applications, International Journal Of Pharmaceutical Studies And Research Ijpsr/Vol. 1(2),2012:1420 .

36) Patel Ss. Liposome: A Versatile Platform for Targeted Delivery of Drugs. Pharmainfo.Net. 2006; 5: 1-5.

37) Deshpande A A, Rhodes Ct, Danish M. Intravaginal Drug Delivery. Drug Development And Industrial Pharmacy 1992; 18: $1225-1279$.

38) Khan Pei,A Brif Review On Development Of Liposomes In Taiwan ,Journal of Medical And Biological Engineering 27(1),53-56

39) Www.Quora.Com/How-Many-Liposome-Based-Drugs-Are-InThe-Market,How Many Liposome Based Drugs Are In The Market? - Quora

40) Patel Rakesh P., Patel Hardik and Baria Ashok H. Formulation and Evaluation Of Liposomes of Ketoconazole International Journal Of Drug Delivery Technology 2009:01-08.

41) Patel Rakesh P., Patel Hardik And Baria Ashok $\mathrm{H}$. Formulation and Evaluation Of Carbopol Gel Containing Liposomes Of Ketoconazole. (Part-II) Available Online On International Journal of Drug Delivery Technology 2009; 1(2):01-04.

42) Patrizia Paolicellia , Federica Correntea, The System SlnDextran Hydrogel: An Application For The Topical Delivery of Ketoconazole, Journal of Chemical And Pharmaceutical Research, Issn No: 0975-7384 : 1-12.

43) Khatry Sadhna , Sirish, Shastri Nalini .Et Al Novel Drug Delivery Systems For Antifungal Therapy, International Journal Of Pharmacy And Pharmaceutical Sciences Issn- 0975$1491 \mathrm{Vol} 2$, Issue 4, $2010: 1-4$.

44) Chetanachan P, Akarachalanon P, Et Al Ultrastructural Characterization of Liposomes Using Transmission Electron Microscope, Advanced Materials Research Http://Www.Scientific.Net (2008).Vol55-57 (2008) :709-711

45) Www.Nanopharmaceuticals.Org, Liposome Nanopharmaceuticals

46) Www.Nanoscalereslett.Com/Liposome: Classification, Preparation, And Applications - Nanoscale

47) Www.Sciencedirect.Com, Medical Applications of Liposomes

48) Www.Pharmasm.Com, Pharma Science Monitor Applications of Liposomes In Medicine

49) Www.Sopharcos.Com/Flexible Liposomes For Topical Applications In Cosmetics

50) Bramhankar D.M. and jaiswal sunil B. Biopharmaceutics and pharmacokinetics, first edition, vallabh prakashn , $2005: 360$ 361.

51) Http://Www.Tnasrl.It/En/Index.Php/LiposomesCharacteristics-And-Applications

52) Www.Asianpharmaonline.Org/ Liposomal World

53) Deshpande Aa, Rhodes Ct, Danish M. Intravaginal Drug Delivery. Drug Development and Industrial Pharmacy 1992; 18: $1225-1279$.

54) Prashar Deepak , Kumar Sanjay , Sharma Surender , Liposomal World-An Economical Overview, Issn- 2231-5705 (Print) Www.Asianpharmaonline.Org Asian J. Pharm. Tech. 2013; Vol. 3: Issue 3, Pg 130-132 [Ajptech.] 130-132 